\title{
Comparison of different methods for evaluating the liquefaction potential of sandy soils in Bandar Abbas
}

\author{
Masood Mosaffa ${ }^{*}$, Moosa Rafiee \\ Department of Civil Enginnering, Hormozgan University, Bandar Abbas, Iran
}

Email address:

Masood_mosaffa@yahoo.com (M. Mosaffa),Moosa.rafiee@gmail.com (M. Rafiee)

To cite this article:

Masood Mosaffa, Moosa Rafiee. Comparison of Different Methods for Evaluating the Liquefaction Potential of Sandy Soils in Bandar Abbas. American Journal of Civil Engineering. Special Issue: Research and Practices of Civil Engineering in Developing Countries.

Vol. 3, No. 2-2, 2015, pp. 30-32. doi: 10.11648/j.ajce.s.2015030202.16

\begin{abstract}
Liquefaction is a phenomenon in which the shear strength of the soil dramatically is reduced or even eliminated in a short time. This phenomenon occurs in non-cohesive, saturation and sleazy soils that have been subjected to ground motions and result of earthquakes. This study compares the results of different methods for evaluating liquefaction potential in the sandy soils of Bandar Abbas coastal city. Based on this, the results of standard penetration test from geotechnical data of two boreholes drilling machine have been used in the coastal city of Bandar Abbas, Iran.
\end{abstract}

Keywords: Liquefaction Potential, Standard Penetration test, Cyclic Shear Stress, Bandar Abbas

\section{Introduction}

One of the biggest devastating phenomenon and main factor damage to structures and technical buildings during earthquake in areas that have been built on sandy soils is reduction or loss of shear strength at the occurrence of soil liquefaction. Thus, the evaluation of liquefaction potential is important. There are two main methods for evaluation of liquefaction potential. The goal of first method is that to model complex interactions in a non-linear site response analysis and by using an appropriate structural model explicitly, and it will be remembered as numerical methods. According to the complexity and the cost and required time, this method can be used more in research studies. The second method is based on the empirical solidarity between seismic loading (the stimulus) and soil resistance against liquefaction (capacity factor), and it is remembered as experimental methods. These methods are compared to numerical models have broader usage due to the simpler use and less expensive. In this method, stimulating factor evaluating ways in determining liquefaction potential are divided into three major groups based on cyclic stress, cyclic strain, and energy. "Fig. 1" shows the method of evaluation liquefaction potential.

In recent years, several empirical methods are represented for evaluating soil liquefaction potential, including methods based on SPT tests, CPT tests or Geoseismic tests by measuring shear wave velocity [6]. This study is paid attention to evaluating of liquefaction potential based on Soil aggregation and SPT number and with cyclic stress method. According to the goal of this paper is used laboratory and out-door data two boreholes drilled in the coastal city of Bandar Abbas for estimating liquefaction potential in different ways, and compares the results at the end of each method.

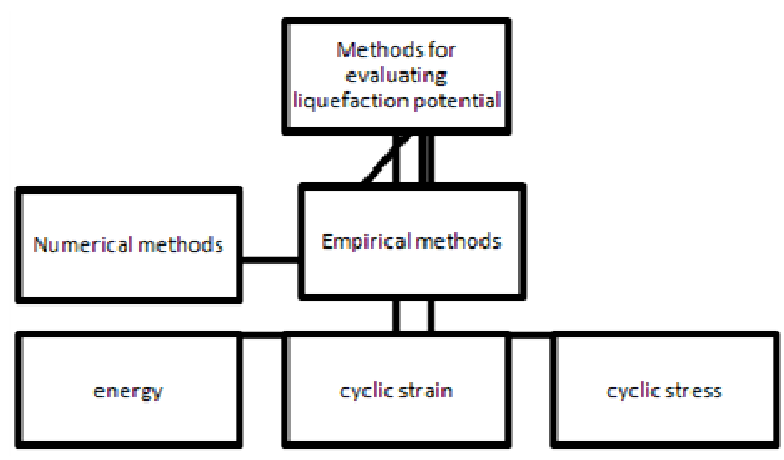

Figure 1. Methods of evaluating liquefaction potential.

\section{Introduction on Geotechnical Boreholes and Research Theory}

For this study, two borehole rings to a depth of $14 \mathrm{~m}$ are drilled in the coastal city of Bandar Abbas, and aggregation, 
hydrometer, Aterberg limits and moisture percent were performed on cheated examples. Outdoor tests of SPT type were performed in every 2 meters. Groundwater level is located at a depth of 2 meters in each borehole.

Summary of the geotechnical results used in this study are listed in Tables 1 to 2 .

In the cyclic stress method that is used to evaluate the liquefaction potential in this research, both stimulating factor (load) and the load (resistance) are expressed in terms of cyclic shear stress. By being tantamount the cyclic shear stress induced by loading to the initial vertical effective stress at the desired depth, the cyclic shear stress ration is defined as in (1).

$$
\operatorname{CSR}=\frac{\tau_{\mathrm{cyc}}}{\sigma \prime_{0}}
$$

The cyclic shear resistance (CRR) is also defined as past cyclic stress being tantamount before start soil liquefaction. Therefore, the potential for soil liquefaction can be expressed in the form of factor of safety ( FS ) against liquefaction:

$$
F S=\frac{C R R}{C S R}
$$

\begin{tabular}{|c|c|c|c|c|c|c|c|}
\hline Depth & Soil Type & $\mathbf{L L}$ & PL & Fine Percent & D50 & Wet Density $\left(\mathrm{kg} / \mathrm{cm}^{2}\right)$ & SPT \\
\hline 2 & Silty Sand & NL & NP & 18 & 0.092 & 1.56 & 9 \\
\hline 4 & Silty Sand & $\mathrm{N}$ & NP & 20 & 0.099 & 1.50 & 9 \\
\hline 6 & Silty Sand & NL & NP & 20 & 0.132 & 1.56 & 13 \\
\hline 8 & Silty Sand & NL & NP & 20 & 0.115 & 1.65 & 17 \\
\hline 10 & Silty Sand & NL & NP & 31 & 0.115 & 1.70 & 22 \\
\hline 12 & Silty Sand & NL & NP & 28 & 0.125 & 1.85 & 33 \\
\hline 14 & Silty Sand & NL & NP & 33 & 0.136 & 1.85 & 37 \\
\hline
\end{tabular}

Table 1. Summary of geotechnical information on soil layers in borehole BH1

\begin{tabular}{|c|c|c|c|c|c|c|c|}
\hline Depth & Soil Type & $\mathbf{L L}$ & PL & Fine Percent & D50 & Wet Density $\left(\mathrm{kg} / \mathrm{cm}^{2}\right)$ & SPT \\
\hline 2 & Silty Sand & NL & $\mathrm{NP}$ & 21 & 0.119 & 1.56 & 9 \\
\hline 4 & Silt & 37.8 & 8.5 & 67 & 0.008 & 1.50 & 13 \\
\hline 6 & Silty Sand & NL & NP & 17 & 0.130 & 1.60 & 16 \\
\hline 8 & Silty Sand & NL & NP & 19 & 0.146 & 1.60 & 19 \\
\hline 10 & Silty Sand & NL & NP & 18 & 0.146 & 1.65 & 25 \\
\hline 12 & Silty Sand & NL & $\mathrm{NP}$ & 18 & 0.165 & 1.87 & 30 \\
\hline 14 & Silty Sand & NL & NP & 20 & 0.158 & 1.87 & 35 \\
\hline
\end{tabular}

Table 2. Summary of geotechnical information on soil layers in borehole BH2

\subsection{Cyclic Shear Stress Ratio}

Here, a simple method was introduced by Seed and Idriss [1] in 1984. It is used for estimating cyclic shear stress induced by earthquake at depth of $\mathrm{Z}$ as in (3).

$$
C S R=0.65\left(\frac{a_{\max }}{g}\right)\left(\frac{\sigma_{v}}{\sigma_{v}}\right) r_{d}
$$

Where $a_{\text {max }}$, maximum horizontal acceleration is due to the earthquake on the ground, $\mathrm{g}$ acceleration of gravity, $\sigma_{v}$ total vertical stress, $\sigma^{\prime}{ }_{v}$ vertical effective stress and $r_{d}$ stress reduction coefficient in depth.

\subsection{Cyclic Shear Resistance Ratio}

As regard to obtaining undisturbed samples of deposits below the groundwater level is not very expensive and available in outdoor tested areas. Therefore, in this study is

Used simpler and more efficient method, standard penetration test. Several relations are presented for calculating the ratio of shear strength by using aggregation graph, Spt number, and sometimes paste limit of soils that are mentioned in this study in four methods:
1- Seed et al. (1983) [2]

2-Tokimatsu-Yoshimi(1983) [3]

3-NCEER Workshop(1997) [4]

4-Japan ' Bridge Code (1991) [5]

\section{Analysis of the Results}

Assuming magnitude of earthquake equal to 7.5 and maximum acceleration at surface equal to 0.3 , safety of factor against liquefaction is calculated and determined based on geotechnical data listed in Tables 1 and 2 at various depths. Note that, (in this paper the details of computational methods for determining the cyclic shear stress and cyclic shear resistance, due to many parameters analysis is ignored). These results are presented in Tables 3 and 4.With regard to consideration of FS ( factor of safety ) equal one in this study, therefore it is observed that up to the depth of 6 meters from surface, soil layers are susceptible to liquefaction. Factor of safety against calculated liquefaction in each of the methods are shown different results, and also significant differences. Therefore, the point is determining the correct safety of 
factor against liquefaction that it should be chosen based on the introduction of earthquake levels and performance of structure. It is noted that if factor of safety is equal to 1.2 in depths of $10 \mathrm{~m}$ in borehole BH1 by Tokimatsu-Yoshimi method [3], soil layer is not liquefaction but soil layer in other methods is able to liquefaction.

Table 3. Summary of liquefaction calculation results in borehole BH1

\begin{tabular}{llllll}
\hline Depth & Soil Type & Fs (Sedd et al) & Fs (Tokimatsu-Yoshimi) & Fs (NCCER Workshop) & Fs (Japan bridge code) \\
\hline 2 & Silty Sand & 1.033 & 0.995 & 1.004 & 2.219 \\
4 & Silty Sand & 0.778 & 0.768 & 0.729 & 1.654 \\
6 & Silty Sand & 0.899 & 0.860 & 0.883 & 1.511 \\
8 & Silty Sand & 1.072 & 1.006 & 1.031 & 1.583 \\
10 & Silty Sand & 1.242 & 1.154 & 1.350 & 1.598 \\
12 & Silty Sand & 1.997 & 1.736 & 2.822 & 1.747 \\
14 & Silty Sand & 2152 & 1.873 & 2.862 & 1.724 \\
\hline
\end{tabular}

Table 4. Summary of liquefaction calculation results in borehole $\mathrm{BH} 2$

\begin{tabular}{cccccc}
\hline Depth & Soil Type & Fs (Sedd et al) & Fs (Tokimatsu-Yoshimi) & Fs (NCCER Workshop) & Fs (Japan bridge code) \\
\hline 2 & Silty Sand & 1.033 & 0.995 & 1.019 & 2.070 \\
4 & Silt & 0.981 & 0.934 & 1.070 & 3.135 \\
6 & Silty Sand & 1.056 & 0.993 & 0.986 & 1.618 \\
8 & Silty Sand & 1.192 & 1.112 & 1.153 & 1.535 \\
10 & Silty Sand & 1.432 & 1.307 & 1.766 & 1.570 \\
12 & Silty Sand & 1.747 & 1.535 & 2.833 & 1.563 \\
14 & Silty Sand & 1.979 & 1.721 & 2.864 & 1.615 \\
\hline
\end{tabular}

\section{Discussion and Conclusion}

This study compares study methods of evaluating the liquefaction potential based on cyclic stress for sandy soils in the coastal area of Bandar Abbas which the following results were obtained.

1-Cyclic shear stress method to evaluation the liquefaction potential as an emprical method and the results are not recommended without numerical analysis.

2-Cyclic shear stress method is not capable to consider accident loads and pore pressure water.

3-The liquefaction potential assessment methods is outlined each with its own strengths and weaknesses. For example, the results of Japan Bridge Code with other methods are considerable.

4-The choice of FS ( factor of safety ) in the soil liquefaction potential is very important So that if not selected based on the performance of structures and earthquake levels correctly, can lead to wrong conclusions in determining liquefaction potential.

5-In the cyclic shear stress method, determining acceleration on the ground is one of the main components for obtained the severity of earthquake which by increasing amount, safety factor against liquefaction is reduced

\section{References}

[1] Seed, H. B., Tokimatsu, K., Harder, I. F., Chung, R. M., "The Influence of SPT Procedures in soil liquefaction resistance evaluation", Earthquake Engineering Research Center Report No. UCB/EERC-84/15,University of California Berkeley,1984

[2] Seed, H.B., Idriss, I.M., and Arango, I., "Evaluation of Liquefaction Potential Using Field Performance Data", J. of Geotech. Eng.,ASCE, 109(3),1983, pp. 458-482.

[3] Tokimatsu, K. and Yoshimi, Y.," Empirical correlation of soil liquefaction based on SPT-N value and fines content" ,Soil Mech. Found., 23(4), 1983, pp. 56-74.

[4] Youd TL, Idriss IM, editors. Proc. "NCEER Workshop on Evaluation of Liquefaction Resistance of Soils". State University of New York at Bu.alo. National Center for Earthquake Engineering. Research, 1997.

[5] Japanese Society of Soil Mechanics and Foundation Engineering, "comparative study on effective stress analysis of liquefaction", Symposium on Liquefaction Remediation Measures.1991.

[6] Port \& Harbour Research Institute, Ministry of transport, "Handbook on Liquefaction Remediation of Reclaimed Land", Japan, 1997. 